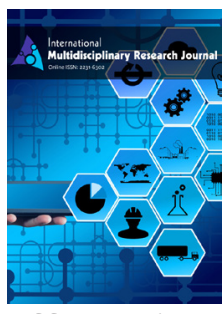

ISSN: $2231-6302$

\title{
Trespassing a fusion of linguistic applications
}

\author{
Mahvish Nisar* and Samia Nisar \\ Lecturer, Sarhad University of Science \& Information Technology, Peshawar, Pakistan Postal address: 25000
}

\begin{abstract}
This research paper aims to explore the cultural, political, and social realities of Pakistan in Uzma Aslam Khan's novel Trespassing. The ethnic conflicts which engulfed Karachi in the 1990s in the aftermath of the Afghan War and Gulf War are also depicted. Mixed approach has been used as a tool in order to highlight different aspects of real life presented in the novel. These approaches are critical discourse analysis, punctuation as prosody of language, code mixing, and color semiotics. Code mixing in the novel gives a glaring picture of Pakistani culture and traditional values at the major level by the use of Urduised words. The application of critical discourse analysis in Trespassing reveals the political unrest, corruption, fantasy for America, individualism and ethnic conflicts which swamped the whole country. The prosody of punctuation illustrates the hidden meanings of the sentences more explicit thus making the societal issues more protuberant. The prosody is concerned with the semantic meaning rather than rhetorical meaning. Color semiotics of both eastern and western culture also objectified and presented a more comprehensive vision of the culture, ideas, and feelings in the novel. Trespassing is a book which is realistic and in all sense an essence of Pakistan and its people.
\end{abstract}

*Corresponding Author:

Mahvish Nisar

Email: mahvishkhan81@gmail. com

KEYWORDS: Code mixing, punctuation as prosody, critical discourse analysis, Pakistani culture, color semiology, mixed approaches

\section{INTRODUCTION}

Discourse is highly dependent upon punctuation marks in conveying effective written communication. According to Deaver (1996), for individual writers punctuations are tools which they use in their respective writings. Punctuations are important components of a structure used within sentences to add clarity in a discourse. The choice of punctuations in a piece of writing by the writers depend upon the meaning the want to convey to the readers. Deaver (1996) explains that the punctuation marks which are like traffic road signs can even destroy a piece of writing if wrongly used.

Critical Discourse Analysis studies political, social and cultural framework of a text. It explores the relationship between social structure of a text and social world. Fairclough (2003) writes that 'CDA sees language as a system of interactionally stimulated signs that help human beings to construct and reconstruct reality'. Van Dijk (2001) affirms that the analysis of a novel from a Sociolinguistic perspective proves that a novel can be fairly called as a discourse. The structural categories of novel varies as the writers have different cultural background.

Semiology or semiotics, is the study of symbols, signs and signification. Color semiotics is divided into three origins: socio-economic origin, cultural origin, and emotional origin.
According to Christian J. Faur colors have "a standard social percept in which specific colors might stand for general mood or idea". The symbolic meaning of color gives an insight of various cultural traditions. Cognition of color makes it easier to understand environmental information for example white is associated with snow, red with fire, brown with mud etc.

Code mixing is the emergence of a third language as a result of mixing of two languages, while retaining grammatical structures and semantics of sentences. Pakistani English is the product of English and Urdu language used by educated Pakistanis in non-native context. Pakistani English has borrowings not only from Urdu but also from other regional languages of Pakistan. Tariq Rahman divides Pakistani English into four varieties: speakers who belong to upper working and lower middle class, and speakers who are professionals and speakers who belong to Westernized elite class. Code mixing has in fact become a characteristics of modern society.

\section{LITERATURE REVIEW}

Rasul (2013) in her article, mentioned that English vocabulary often borrowed and blended in Urdu which is the national language of Pakistan. Pakistani English has become an important element of educational institutes, text books, magazines and newspapers. She further states (2009), that globalization of 
English has let no language to escape from its penetration. Communication and media channels also played a crucial role in the exposure of English language. The repeated code switching and code mixing and code mixing of English in Urdu has resulted in the absconding of certain lexical items. The so much obtrusion of English into Urdu has sometimes made it difficult to differentiate these lexical items as they repeatedly interchange.

Ahmed et al. (2015) attempted to highlight the trends and functions of code-switching and code-mixing among Urdu EFL college students in Districts Okara and Chishtian, Punjab, Pakistan. The study has shown positive attitude of students towards code-switching and code-mixing in Urdu EFL class.

Bilal (2012) described five modes of discourse as identified by Smith (2003) i.e. Narrative, Report, Descriptive, Information and Arguments. In the present research paper, he gives a synopsis of the story, "The Gift of Magi”. Della and James are the main characters of the story who sacrifice their personal precious things to present gifts to each other on Christmas Eve. Wealth and Poverty, Generosity, and Love are the main themes of the story as described by the researcher. As for as his practical analysis is concerned, he discusses foregrounding and back grounding in the text. Patterns of organization in the text, situation entities, and text progression, and subjectivity in the text are other main points described by the researcher. He is of the view that this kind of research is helpful in the understanding of a text through syntactic structures and linguistic features.

Paziraie (2012) used qualitative, quantitative, corpus based, descriptive and applied eclectic approach to discourse analysis at the micro and macro levels for her analysis. Discussing translation, she opines that it is mainly a change of form. And the forms can be the spoken or written actual phrases, clauses, sentences or paragraphs. For her, the discourse analysis can be carried out within a variety of social science disciplines including linguistics, sociology, and communication. Therefore, since discourse analysis may be applied to scrutinizing the texts and decompose them, it is very important in translation. So, translators can use discourse analysis as a suitable tool to analyze the source texts, for achieving good understanding of them, and target texts, to evaluate the quality of their translated texts. Things Fall Apart is a post-colonial novel hence the researcher briefly discusses history of post-colonial literature and gives a credit to Edward Wadie Said's masterpiece "Orientalism" and Joseph Conrad's "Heart of Darkness" also. Discussing translation, she tells that the Arabs promoted it greatly in $8^{\text {th }}$, $9^{\text {th }}$ and $10^{\text {th }}$ centuries. She analyzes the novel at micro and macro level. She also gives a comparison of translator's judgment of the novel. She claims that by applying model of discourse analysis, the translation teachers and students can analyze the texts accurately and can understand how far their translations are coherent.

Punctuation enriches communication. It is vital to disambiguate the meaning of sentences. According to Ehrlich (1987) Punctuation marks are symbols used in writing to indicate a pause within a sentence, to show that a sentence has come to an end, to bring out clarity in sentences and to help one decipher the intended messages.

Alva Dhal (2015) presented a case study on one of the functions of punctuation: the separation and expression of voices. In her study she shows that an awareness of punctuation can widen the understanding of discourse presentation and viewpoint, and how in silent reading a reader is able to disentangle the complex interplay of voices in a novel. A dialogical, Bakhtin-influenced approach is taken, and presented as potentially useful to many stylistic studies. Using the Bakhtin "sociological stylistics" approach she studied the linguistic details in the utterances they belong to. She analyzes that dialogical and interactional perspectives on the language of novels can create spaces for interdisciplinary insights, and integrate our understanding of text and context.

Albert E. Krahn (2014) in his study argues that neither rhetoric nor grammar is directly the basis for punctuation. Rather, it responds to a schema that determines the order of the words in spoken and written English, and it is a linguistic concept without question. The intent instead was to reveal another way of looking at writing as a graphic system that displays the canonical sentence using gestalt visual techniques. He puts aside the rhetorical/prosodic/elocutionary and grammatical approaches by accepting written English and its sentences and partials as a visual representation of the language which has its own linguistic way of displaying the punctuation.

\section{RESEARCH OBJECTIVES}

The objectives of this study are:

1. To analyze the norms, culture, and socio political issues of Pakistani society in general, and Karachi in particular.

2. To apply code mixing phenomena in order to explore religious, traditional, and cultural connotations in the text through words.

3. To assess the link between text and society. This can be done by using the technique of critical discourse analysis and punctuation as prosody of language.

\section{RESEARCH METHODOLOGY}

This research study follows both qualitative and quantitative approaches. The data is collected from Uzma Aslam Khan's novel Trespassing. The highly marked conversations of the characters, the application of punctuation, and use of Urdu words to be analyzed by using mixed approach i.e. code mixing, punctuation as prosody of langauge, and critical discourse analysis. The tabulation of Urduised words has been done on quantitative method, while all discussion has been done qualitatively. Whole of the novel will not be analyzed, only certain chunks are segregated. These chunks will be those words, sentences, and paragraphs which highlight Pakistani society, its norms, and its socio political conundrums, and its effects on Pakistan's ethnic hub, Karachi.

The following techniques are involved in analyzing the novel:

1. The text is analysed to trace different types of code mixing drawn upon the conceptual frame works developed by 
Flower and Muthiah and the earlier models offered by Kachru, Baumgardner, Kennedy, and Shimim. The Urduised words were selected from the novel and tabulated. The frequency of these words were also recorded. Each word was then analysed according to its meaning and usage in the context.

2. The inner meaning of the sentences is analysed in order to highlight the social practices of Pakistani society through the application of Wallace Chafe theory of punctuation as prosody of language. His theory is based on exploring the role of punctuation: as prosody of inner voice, expressing their intentions, or to call for an awareness of something.

3. The technique of critical discourse analysis is applied to reveal different aspects of real life in the novel on the basis of Norman Fairclough's three dimensions of discursive practices. Those passages from the novel are selected which reflect issues of society and its norms.

\section{PUNCTUATION AS PROSODY OF LANGUAGE}

Punctuation marks in Trespassing aided in resurfacing hidden meanings in sentences. The implementation of punctuation as prosody of language technique by the writer, deviant as well as non-deviant, aims at unveiling Pakistani society and its issues more observably. The prosody of punctuation in the novel served as tools for the writer to communicate her thoughts to her readers, it became an expression of her inner voice. These punctuations for Uzma Aslam Khan exercise as questions, perspectives, revelations, uncertainties, and a voice raised against injustices. In Trespassing they function semantically rather than phonologically and rhetorically.

\section{Italicization}

Khan's objective narration of political, societal, and ethical issues are highlighted through the practice of italics in Trespassing.

i. The double standards of most of those Pakistani men related to choosing their wife is depicted in italics:

He'll have fun with foreign women but marry a local one to please his mother. (p. 285)

Foreign women liberalism and boldness would excite them but when it comes to marriage they would prefer a spouse selected by their mother whether they like her or not. Wife for these men is like a commodity with whom they would have children but all their love and happiness would be tilted towards their girlfriends in foreign land.

ii. The English newspapers headlines are also in italics to draw the readers' attention towards the social problems faced by the people of Pakistan.

Seven Years Into Soviet Invasion, Refugees Keep Pouring In...

MQM Calls For Strike... More Buses Set Ablaze...Women Protest

Hudood Laws. Jamaat-i-Islami Calls For Anti-Soviet Rally. (p. 239)

iii. The speech of different characters are also in italics in order to reveal the enmity of different ethnic groups towards each other:
This Pathan son-of-an-owl knows he has the best collection in his Godforsaken nuthouse.

We should crack his skull.

We can get the bullets lodged inside it. (p. 248)

\section{Bracketing}

Brackets in Trespassing not only disclose characters' feelings but at the same time writer's own opinions and judgments. Use of brackets in the novel is to emphasize issues faced by Pakistani society through the lenses of the writer.

i. In any successful marriage marital adjustment plays a crucial role. One of the many reasons of unsatisfied married life is also education gap between the spouses. As a result there is less communication between the spouses and almost no understanding. This issues has been illustrated through the characters of Anu and the doctor. Anu is unable to understand doctor's unique way of giving gifts. For her they were her "husband's unsettled ways":

The doctor had never presented a gift in wrapping paper...He left it

where he believed it belonged.... Anu knew nothing of this. When the doctor presented her with gifts that popped up in plant pots, spice jars, lipstick tubes (a meter of resham so fine it fit in the finger-sized cylinder perfectly, so when Anu twirled it, out sprang the cloth, softly on her cheek, exactly as the doctor had envisioned)... (p. 55, 56)

ii. In Pakistan the perspective of men towards women have also been specified. They have placed women in different categories:

So, when he's had his fun, to pacify his guilt, he'll be ultra-protective of Ami jaan (who'll symbolize his nation), and ultra-conservative with his wife (who'll symbolize his authority in the nation). (p. 93)

iii. Khan also draws her readers attention towards the major issue faced by new students in west in college hostels is to have a roommate who turns out to be alcoholic. This is one of the most common and serious issue faced by educational institutes in west. Students who have alcoholic roommates are more likely to get addicted.

...woke at seven after a bad night (his roommate came home drunk at three in the morning again, and with his usual timely expertise, proceeded to vomit once inside the door)... (p. 28)

\section{Em dash}

Em-dash also assisted the writer in conveying issues related to society. Her purpose is to make the issues more explicit by letting her readers redefine what is being written. Instead of evolving emphasis she wants to draw her readers' attention towards societal issues.

i. Khan points out the status of a house wife in Pakistani culture and where she stands even

after years of marriage. Khan wanted to convey that women as house wives have no identity of their own. They have no rights over their husbands except for their mother-in-laws and sisters. This is not only in case of love marriages but also in case of 
arrange marriages, and is beautifully illustrated through the character of Anu and her place in the life of the doctor.

His sisters continued to sob and exchange stories from their childhood,

all of which proved how they knew him better than she did-the woman he'd

wedded, by their own arrangement, twenty-three years ago. (p.78)

ii. Issues related to security in Pakistan are exquisitely stressed in Trespassing. Hiring house servants or security guards is a hard task in Pakistan. Situation in Pakistan has become such that people who belong to upper class hire security guards for their protection, but sometimes these guards become the one to murder their employer for different reasons. Number of incidents have been reported related to murdering or stealing from employer at the hands of security guards and house servants. Whenever Dia would travel she would be escorted by two armed guards. Even then she would have a sense of insecurity whether to trust them or not:

In the last five years she often wondered which was the greater risk-going

with or without them. (p. 98)

iii. The ethnic differences which have been resulted from economic and political instability is also presented by using the technique of em dash. Salaamat who is from different ethnic group is being laughed at by his fellow workers:

Everything about him-his looks, accent, language, carriage-was mocked

and shredded by thirty or so workers... All of them belonged to one of two groups.

The Punjabis...the Pathans. (p. 131)

\section{Interrogatives}

The questions put by the characters are not just to convey their psychological attitude but also highlight the social issues to the readers. In fact the question mark for Uzma Aslam Khan is a symbol of uncertainties for which the Pakistani society has been so far unable to provide any answers.

i. Anu recalls as how the doctor never shared or discussed anything with her all those years she waited for his attention and love:

Where was his love? In all those high-society parties he dragged her

to, just to embarrasses her?

In the food he never liked?

The conversation he never made?

Her lineage? His want of it? (p. 77)

These are the questions which majority of Pakistani house wives have in their minds. Once married she has no rights or freedom of expression. She is merely a puppet. She cannot breath or speak without her husband's permission. She doesn't deserve to be praised, loved, or have her wishes be fulfilled. She is a house-hold thing whose only work is to cook and look after the children.

ii. Trespassing also puts light on the women of this generation. They are educated, independent, free thinkers, and no longer wanted to be felt inferior. Their awareness has made them to question the norms of this society. Dia incarnates women of this generation putting question to Nini's sacrifice of her freedom of choice to others decisions:

Why should Nini accept the limits that others so maliciously

placed upon her? (p. 105)

\section{Exclamations}

Exclamation marks in Trespassing reveals psychological and characteristic traits of the people of Pakistan, and at the same time for the Khan it functions as a voice raised against societal issues.

i. Dia while talking to Nini on the phone was also watching a commercial on the TV related to skin whitening cream:

Dia tilted her head and saw the

TV: two women were waiting to be interviewed for an airhostess's job... The one who got it revealed her secret to the loser: a tube of skin-whitening cream. Now she could fly! (p. 91)

The exclamation mark not merely convey excitement but in fact it is Khan's voice raised against the colonial mind set of the people of this country. The use of exclamation here shows Pakistani people's obsession for fair skin, and they still being slave to colonialism. Such commercials promote the idea that women even if not intellectually bright can still have new doors of opportunity opened for them by having fair skin. Cosmetic industry and media also play a vital role in promoting such idea.

ii. The concern for the prosperity of this country is also depicted through the technique of exclamation. Daanish, on his arrival to the Water office saw a huge crowd pushing ad nudging each other. Each one of them wanted to reach the table of the officer. He got frustrated:

How will our nation prosper if we can't even make a line! (p. 329)

Here the exclamation function as a voice concern at the fate of the country whose citizens are disorderly, unsystematic, and careless towards their responsibilities.

iii. The characteristic traits of the people of Pakistan are also depicted through the technique of exclamation:

'I had my hair set there just yesterday. And you won't believe who was having hers done beside me!' She looked around expectantly. 'Babara!'.... And I found out that her grandmother was my grandmother's neighbor's khala's mother-in-law's best friend's sister!' (p. 71)

Pakistani people if by accident come across famous personalities they love to relate themselves to them as if these personalities were there close relatives.

\section{Ellipses}

Khan use ellipses by deviating from its traditional function. Instead of leaving the sentence incomplete she first let her readers comprehend according to their perception and before their minds sway in different directions, she provides them with the answer which she wanted to impart. Another uniqueness of this technique is the argument is put by one character and the answer is comprehended by another character. This shows 
that the characters of Uzma Aslam Khan have the ability to read each other's minds.

i. Nini when advising Dia that a woman in this society at the end will surrender to its norms no matter how high she aims. If she don't she'll be alienated just like, here Nini leave the sentence incomplete for Dia to be comprehended and answered, which is just like her mother.

It's okay to aim higher, or have dreams.

And where do dreams get us? Nini shook her head. 'I worry about you. If you're not careful you'll end up lonely, like...

Oh please, Dia cut her off. Like Ama? She used to be our role model, remember? (p.114)

\section{SEMIOTICS OF COLOR IN TRESPASSING}

Uzma Aslam Khan applied all the three origins of color such as: its cultural origin, socio-economic origin, and its strong emotional effects influencing the psychological state of a person.

i. The bold and fun-loving nature of Daanish's father is depicted through scarlet colouZZr. Khan here explores the emotional state of the character through color by taking its origin from west. Daanish remembers the enthusiasm and love of life of his father when he saw scarlet colour clouds from the plane on his return from America to attend his father's Qul:

Perhaps his father's spirit dwelled among the scarlet clouds, and would drift through this very plane. (p. 21)

ii. Gray color in Pakistan signifies old age, grief, and depression. Again the psychological state of the character is depicted. The gray-hooded crow describes the mental state of Daanish when he entered his refurbished room. His father's memories were completely erased. He felt a sense of loneliness. The room was boring and depressing. The feeling of indifference of Daanish towards his room is beautifully depicted by Khan by using gray colour:

A crow perched on the windowsill. It was large and gray-hooded. (p. 57)

iii. The red colour leaf shows Daanish's love for this girl and the yellow colour leaf signifies his happiness which he feels when in her presence. But for Annu it signified marriage because brides in Pakistan wear red dresses for their weddings, whereas, yellow colour is worn on Mehndi by the bride which is an important event of Pakistani marriages. This picture made her worried:

There was a girl leaning against a tree. Red and yellow leaves scattered all around her. (p. 82)

\begin{tabular}{|c|c|c|c|c|}
\hline S. No. & Word & Meaning & Origin & Frequency \\
\hline 1. & Maulvi & Muslims religious scholar. & $\begin{array}{l}\text { From Urdu moulvi and Arabic mawlawījudicial' } \\
\text { and from mawlā 'mullah'. }\end{array}$ & 1 \\
\hline 2. & Siparas & A division of Quran into thirty parts. & Its origin is from Persian word Siparah. & 2 \\
\hline 3. & Kameez & A long shirt worn by people of India and Pakistan & $\begin{array}{l}\text { From Arabic word qamīs which is from Latin word } \\
\text { camisia. }\end{array}$ & 3 \\
\hline 4. & Khaki & $\begin{array}{l}\text { Dull yellowish-brown colour cloth used to make uniform } \\
\text { for soldiers and postmen. }\end{array}$ & $\begin{array}{l}\text { Originated in mid- } 19^{\text {th }} \text { century from Urdu and } \\
\text { Persian word khāk which means dust. }\end{array}$ & 1 \\
\hline 5. & Sari & $\begin{array}{l}\text { A very long piece of lightweight cloth wrapped around the } \\
\text { body with one end swathed over one shoulder or head. }\end{array}$ & It is from Hindi word sārī & 1 \\
\hline 6. & Chapaatis & $\begin{array}{l}\text { A South Asian staple food made from wheat flour and } \\
\text { cooked on a skillet. }\end{array}$ & $\begin{array}{l}\text { An Urdu word originated from Hindi word capātī, } \\
\text { from capānā which means flatten. }\end{array}$ & 1 \\
\hline 7. & Khichri & A South Asian dish prepared from rice, lentil, and spices. & $\begin{array}{l}\text { Originated from Sanskrit khiccā, a dish of rice } \\
\text { and legumes. }\end{array}$ & 1 \\
\hline 8. & Mutton korma & $\begin{array}{l}\text { A dish of lamb, meat, and chicken braised with water, } \\
\text { stock, and yogurt or cream added. }\end{array}$ & $\begin{array}{l}\text { From Urdu word kormā or kormah, which in turn } \\
\text { originated from Turkish Kavurma, meaning cooked } \\
\text { meat. }\end{array}$ & 1 \\
\hline 9. & Supari & $\begin{array}{l}\text { A mixture of spices such as cardamom, menthol, betel } \\
\text { nuts, coconut, and other flavors. }\end{array}$ & Origin is from Hindi supārī & 1 \\
\hline 10. & Curries & $\begin{array}{l}\text { A South Asian dish which have vegetables or meat cooked } \\
\text { in a flavorful spicy sauce. }\end{array}$ & $\begin{array}{l}\text { Origin of the word is from Tamil kari which mean } \\
\text { sauce. }\end{array}$ & 1 \\
\hline 11. & Halwa & A dessert which is cooked from Semolina (Suji). & From Arabic kalwá which means sweet confection. & 2 \\
\hline 12. & Chacha & It means father's brother & From Hindi word cācā. & 6 \\
\hline 13. & Bhai & It means brother. & From Hindi bhāi, from Sanskrit bhrātr 'brother'. & 3 \\
\hline 14. & Bibi & A surname and nickname given to a woman in South Asia & Origin is from Urdu and Persian bībī. & 2 \\
\hline 15. & Ehmak & It means foolish or silly. & Originated from Arabic word ah̆maq. & 2 \\
\hline 16. & Hai Hai & Used to express grief, regret, or horror. & From Hindi word hāy woe. & 1 \\
\hline 17. & Shabash & It means well done. & Originated from Urdu and Persian šābāš. & 1 \\
\hline 18. & Mynas & A bird of the starling family. & $\begin{array}{l}\text { Originated from the Hindi word mainā in the } \\
\text { mid- } 18^{\text {th }} \text { century which itself is originated from } \\
\text { Sanskrit madanā. }\end{array}$ & 1 \\
\hline 19. & Chamak pati & Brightly coloured reflective tape used in truck art. & $\begin{array}{l}\text { From Urdu words where chamak means shinny and } \\
\text { pati or patti means sheet. }\end{array}$ & 1 \\
\hline 20. & Jamun & $\begin{array}{l}\text { A purplish edible fruit of an evergreen tropical tree of } \\
\text { family Myrtaceae. }\end{array}$ & $\begin{array}{l}\text { Is originated in early } 19^{\text {th }} \text { century from Hindi word } \\
\text { jāmun. }\end{array}$ & 1 \\
\hline 21. & Shaadi & South Asian weddings. & From Urdu and Persian šādā. & 1 \\
\hline
\end{tabular}


iv. Gold colour symbolizes success and extravagance which reveal his thoughts related to America where his carrier lies. The meaning of gold colour is similar in all cultures i.e. wealth. Here the socio-economic origin of the color is explored.

The sky turned from sepia to gold. (p. 26)

\section{CRITICAL DISCOURSE ANALYSIS}

Critical discourse analysis in this novel brings to surface cultural, political, and social norms of Pakistani society. Trespassing is a socio-political discourse in every sense. The turmoil's of Pakistani society is discussed through the characters. These characters are from the different shades of real life. Fatah's hate speech depicts as how this country is controlled by the foreign forces. This country is ruled by ethnic chaos and class differences:

“The Koreans took your sea, but you learned nothing. The Punjabis took your sweat, still you learned nothing. The Urdu-speakers burned your bus: nothing. The Pathans took your first pay: nothing again. It's not just land and sea they all want. They want the air we breathe. And what does this country do? It begs them to take it. It says, please, please, stick millions of dollars into our fat bottoms and own us all! Just let me keep my car, my house, my job.No, If you don't control them, they control you (p. 376)."

The speech of Daanish reflects the helplessness of poor countries in front of powerful ones:

"While poor countries are punished for defending themselves, the strongest military power in the world comes up with excuses to keep building its weaponry.... The biggest problem is that we require aid at all. Beggars, that's what we are. We can either join the bullies or stay beggars. Those are our two choices (p. 132)."

\section{CODE MIXING IN TRESPASSING}

Code mixing in Trespassing is a medium of imparting Pakistani culture to the rest of the world. The Urduised words serve significant intent in the novel. Subsequently, they have their tantamount available in English language. The core reason is that these Urduised words not only illustrates writer's rich cultural association but are also an epitome of Pakistani English engross in customs and traditions of Pakistan.

This novel has Urduised words for religious beliefs, for attire, for food and drinks, for relationships, and for emotional and psychological states, and other miscellaneous words. All these words sketch Pakistan and its culture in an elaborate manner to foreign readers. The code mixing of Urdu words in Trespassing by Uzma Aslam Khan consign lexical richness to the novel. The following table shows this:

\section{CONCLUSION}

The application of mixed approach i.e. critical discourse analysis, code mixing, punctuation as prosody of language, and color semiotics of Trespassing leads to the scanning of the novel as a complete picture of Pakistani society, its people, and its political and ethical conflicts. This analysis aided in revealing the novel not merely a fictional world but a canvas of real life and real people from every walk of life. Critical discourse analysis explored the social and political mores of the society. This approach spotlighted the corruption which looms the government offices; relationships that trespass the religious and cultural boundaries; ethical conflicts dominating the streets of Karachi and above all a tale of illicit romance heading nowhere. Code mixing approach is a peculiar feature of Pakistani English writers. The practice of Urduised words in Trespassing has given a local touch to the novel. Code mixing has now a days become a very successful approach by Pakistani novelists for communicating cultural norms and traditions to the foreign readers. It is also concluded that punctuation also played an integral part in highlighting different facets of Pakistani society. Punctuations let to resurface the hidden meanings in the sentences. It lime lighted the security issues, women's fate in a male dominated society, and habits and behavior of people of Pakistan by playing the role of inner voice of the writer. The fusion of eastern and western symbolic application of colors by the Khan has let to express the coded information. All in all these approaches depicted the Pakistani society undoubtedly in its true colors.

\section{REFERENCES}

Ahmed, R. Ahemed, R. Seemab, G. (2015) Concepts of Code Switching and Code Mixing as Facilitators in Urdu EFL class. Journal of Policy Research, 62-66.Deaver, B. (1996). Punctuation for better writing. UK: Simply Media Publishing Ltd.

Fairclough, N. (2003) Analysing Discourse: Textual Analysis for Social Research, London: Routledge

Faur, C. J. (n.d.). The Semiotics of Color. Retrieved from http://www. christianfaur.com/color/Site/Color\%20Semiotics.html

Bilal, H. A. (2012). Discourse Analysis of the gift of the magi. Academic Research International.

Dahl, A. (2015). The separation of voices in a literary utterance: a dialogical approach to discourse presentation, viewpoint, focalization - and punctuation. Uppsala University.

Dijk, T.A. (2001). "Critical Discourse Analysis". In D. Tannen, D. Schiffrin, and H. Hamilton (eds), Handbook of Discourse Analysis. Oxford: Blackwell

Ehrlich, E. 1987. Schaum's outlines of theory and problems of punctuation, capitalization, and spelling. New York: McGraw-Hill.

Krahn, A. E. (2014, 05 01). A New Paradigm for Punctuation. UWM Digital Commons.

Paziraie, M. E. (2012). A discourse of the novel "things fall apart" and two of its Persian translations at micro \& macro level. English Linguistic Resaerch.

Rasul, S. (2013). Borrowing and Code Mixing in Pakistani Childern's Magazines: Practices and Functions. Pakistaniaat: A journal of Pakistan Studies.

Rasul, S. (2009). Code- Mixing and Hybridization in Pakistan- Linguistic, Sociocultural and Attitudinal Perspectives. Germany: VDM

Smith, Carlota. (2003). Modes of Discourse: The Local Structure of Texts. Cambridge, Cambridge University Press. 